\title{
The Effects of Metals and Inhibitors on Thermal Oxidative Degradation Reactions of Unbranched Perfluoroalkylethers
}

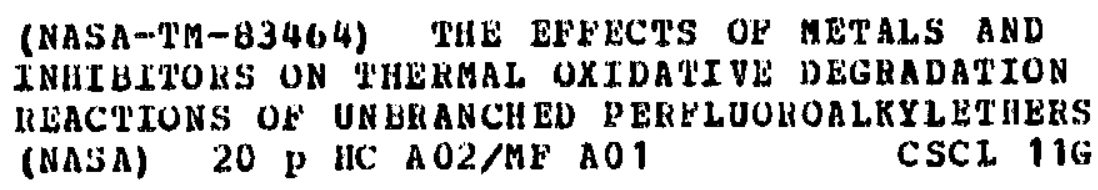

William R. Jones, Jr. Lewis Research Center Cleveland, Ohio

and

K. J. L. Paciorek, D. H. Harris, M. E. Smythe, and R. H. Kratzer Ultrasystems, Inc. irvine, California

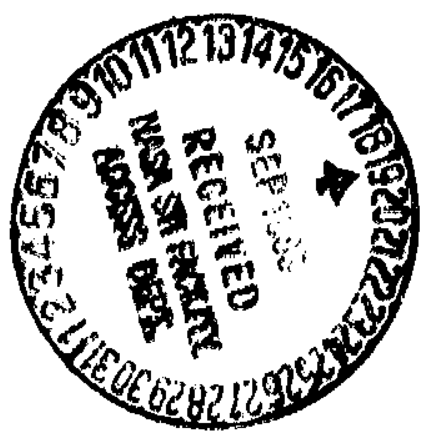

Prepared for the Sixth Winter Symposium on Fluorine Chemistry sponsored by the American Chemical Society Daytona Beach, Floride, February 6-11, 1983

\section{NASA}


THE FFFECTS OF METALS ANI INHIBITORS ON THERMAL OXIDATIVE

DEGRADATION REACTIONS OF UNBRANCHED PERFLUUOROAI.KYILETHERS

Will lam R. Jones, Jr.

Nattonal Aeronautics and Space Admintstration

Lewis Research Center

Cleveland, Ohto

and

K. J. I. Pactorek, D. H. Harris, M. E. Smythe, and R. H. Kratzer

111 trasystems, Inc.

Irvine, California

\section{ABSTRRACT}

Thermal oxidative deyradation studies were performed on unbranched pert luorealkylethers at $288^{\circ} \mathrm{C}$ in oxygen. Metals and alloys studied included $\mathrm{Ti}_{\mathrm{i}}$ $\mathrm{Al}$, and $\mathrm{Ti}(4 \mathrm{Al}, 4 \mathrm{Mn})$. The mechanism of deyradation was by chain scission. $\mathrm{Ti}$ and $\mathrm{Al}$ promoted less degradation than $\mathrm{Ti}(4 \mathrm{Al}, 4 \mathrm{Mn})$. The two inhibitors radation rates by several orders of mane and a phosphatriazine) reduced degtor the same duration ( 75 to 100 of maynitude. Both inhibitors were effective more surtace protection.

\section{SUMMARY}

Thermal oxidative deyradation studies were performed on an unbranched class of perfluoroalkylethers (Fomblin 2 ). Tests were conducted in oxygen at $288^{\circ} \mathrm{C}$ with the neat fluid and in the presence of pure titanium, pure alumin-

The mechanism of deyradation of the unbranched perfluoroalkylethers in the presence of metals was chain scission. The pure metals (titanium and alu.. minium) promoted less degradation than the alloy, Ti $(4 \mathrm{Al}, 4 \mathrm{Mn})$.

Two inhibitors (a perfluorophenyl p'losphine and a phosphatriazine) reduced deyradation rates in the presence of metals (based on the quantity of volatile products formed) by several orders of magnitude. Both inhibitors concentration. However, the phosphen ( 75 to $100 h^{n}$ ) ai a 1 percent by weight metal surfaces.

\section{INTRODUCTION}

Pertluoroalkylethers are a class of tluids which exhibit excellent thermal and oxidative stability (refs. I and 2). Combined with yood viscosity
characteristics (ref. 3), good elastohydrodynamic film forming capabilities
(ref. 4), good boundary lubricating ability (rots ity properties (ref. 6) make these ability (rets. 3 and 5), and nont lammabilperature lubricant applications. 
Basically, there are two types of perfluoroalkylethers, an unbranched (ref. 7) and a branched class (ref. 1). The most importiant representatives of the branched materials (fig. $1($ a)) are dertved from hexafluoropropene oxide temperaturese compositions suffer some deftciencies. In order to satisfy low tion, the poly (hexaf volactiticy problems are encountered (ref. 8). In addibility with ferrous and coprope oxides) were found to exhtbit poor compati-

The mechanism responsible for the low temperature $\left(<316^{\circ} \mathrm{C}\right)$ incompatidility has been studied (ref. 9) and was found to be due to the presence of -3 percent unstable chains. These chains were shown to be hydrogen (ratner than removal of these chains byosure of HFPO fiudds at $343^{\circ} \mathrm{C}$ in oxygen resulted in deyraded oy oxygen at 343 volatilization. The resultant fluid was not $316^{\circ} \mathrm{C}$. However, degradation

A new class of perfluoroalkylethers based on the photo-oxidation of fluoro-oletins (ret. 7) has been developed. These materials, whose general chemical structure appears in figure 1(b), are unbranched and have better viscosity-temperature properties than the branched (HFPO) products (ref. 8). pared to the HFPO fluids fluids exhibit lower thermal oxidative stability combonding in both classes (ref. 8). This is surprising since the chemical that tertiary carbon-f lunrine bonds are. In fact, it has been shown (ref. 10) involving primary or secondary carbon normally less stable than those that the HFPO fluids (which contain atoms. This would lead one to conclude stable than the unbranched materials.

A preliminary thermal oxidative stability study has been performed on these fluids (ret. 11). The effects of metals (M-5C steel and $\mathrm{Ti}(4 \mathrm{Al}, 4 \mathrm{Mn}$ ) alloy) and inhibitors (a monophospha-s-triazine and a perfluorophenyl phos-

The unbranched fluids were found to be inherently unstable at $316^{\circ} \mathrm{C}$ in an oxidizing atmosphere. This instability was not due to the presence of hydroyen chain termination or peroxide linkayes. Metals greatly increased the rate of deyrad ion in oxidizing atmospheres; however, degradation inhi'jitors were highly ef: cctive in arresting degradation at $288^{\circ} \mathrm{C}$. At $316^{\circ} \mathrm{C}$ the
eftectiveness was limited.

The objective of this work was to continue the study of the thermal oxidative deyradation processes of the unbranched cype of perfluoroalkylether fluids, in particular to determine the influence of alloys versus pure metals upon deyradation and to assess the effectiveness of the degradation inhibitors both with respect to concentration and test duration.

\section{EXPERIMENTAL FLUID}

The unbranched perfluoroalkylether fluid used in this study is manufactured by Montecatini Edison under the trade name Fomblin $Z$. Two different 196. These are fluid were studied which are designated MLO-72-22 and MLO-79. the year in which the fluid was received. 
Two different degradation inhtbitors were used in these studies. One was a perfluoroalkylether substituted perfiuorophenyl phosphine (fig. 2(a)). Results with this additive have been previously reported (ref. 12) where it: was designated as P-3. The second additive was a perriluoroalkylether sulustituted monophosphars-irtaztre (fig. 2(b)) (ref. 13). Thts addtive will be designated at: $\mathrm{C}_{2} \mathrm{PN}_{3}$ for conventence.

\section{OXIDATION - CORROSION APPARATUS}

The inicromoxidation corrosion apparatus is a modified version of the type reported by Snyder and Dolle (ref. 3). The decomposition tube contiguration and the rod assembly for nolding tine metal coupons are schematically shown in figures 3 and 4 , respectively. The coupons were $9.5 \mathrm{~mm}(3 / 8 \mathrm{in.})$ ob and 3.2 $\mathrm{mm}$ (1/8 in.) ID. These were obtained from Metaspec Co.. San Antonio, Texas. For heating sample tubes in a vertical pesicion, a modified Lindbery HeavyDuty box furnace was used. In this arrangement, $180 \mathrm{~mm}$ of the $420 \mathrm{~mm}$ of tube length were at test temperature; the fluid occupied, at most, the lower $75 \mathrm{~mm}$ (tig. 3). The extra yas reservoir was in the ambient environment.

Prior to testing the metal coupons were polished using first, Norton NoFil Durite finishing paper Type $4220 \mathrm{~A}$, followed by open coat silicon carbide papers grades $400 \mathrm{~A}$ and $500 \mathrm{~A}$, respectively. Subsequently, the metal coupons were washed with Freon 113, dried, weighed, and suspended in the test apparatus (see tig. 4). After the completion of a given experiment, the metal coupons were washed with Freon 113, dried in an inert atmosphere chamber, then weighed and visually inspected. The used coupons were subsequentily sealed in Mylar envelopes.

In a typical experiment, the fluid was introduced into the decomposition tube (see fiy. 2) which was then evacuated and filled to a known pressure at a known temperature with oxygen. Since the apparatus was calibrated and the fluid volume measured accurately, the quantity of gas introduced was exactly known. The decomposition tube was then inserted into the preheated box furnace for a specified period of time; during this exposure the temperature was continuously recorded. After removal from the furnace, the tube was allowed to cool to room temperature, attached to the vacuum line, and opened. The liquid nitrogen noncondensibles were collected quantitatively, measured, and analyzed by gas chromatography and infrared spectroscopy. The liquid nitrogen condensibles, which were; volatile at room temperature, were measured, weighed, and analyzed by intrared spectroscopy and mass spectrometry. The fluid residue itself was weighed and subjected to infrared spectral analysis; in selected instances, molecular weight and nuclear magnetic resonance (NMR) determinations were performed.

The degradation rate is calculated from the amount of liquid nitroyen condensibles formed and is reported as milligrams of condensible product per yran of oriyinal fluid per hour. 


\section{DEGRADATION STUDIES}

\section{Effect of Metals}

Previous work (ref, 11) has shown that the unbranched perfluoroalkylether tionds are trinerentily unstabie at $316^{\circ} c$ in oxidizing atmospheres. In addigreatly accelerated this degradation. the fluid in oxtdiditing atmospheres at $288^{\circ}$ the present study, the behavior of and alloys was evaluated. Tests were run $c$ in the presence of pure metal s titanium (TH) and pure aluminum (AI) coupons. formation for these tests appear in figure 5. Rates of condensible product

The batch employed in this test series (MLOm79m196) hehaved similarly to the previous batch (MLO-72-22) reported in ref. 11 . Repeat tests in the rates. The arrows in tigure 5 indicate $\mathrm{Mn}$ ) yieided comparable degradation with the pure metals yielded definitely continuations of the same test. Tests the alloy ( $\mathrm{TI}(4 \mathrm{Al}, 4 \mathrm{Mn})$ ). It is not lower degradation rates compared to increased witn time for titanium but decreased for the degradation rate

\section{Effect of Degradation Innibitors}

Previously reported work (ref. 11) had shown that two inhivitors, a perfluorophenyl phosphine ( $P-3)$ and a phosphatriazine $\left(C_{2} \mathrm{PN}_{3}\right)$ were highly oxyyen at $288^{\circ} \mathrm{C}$, but had onltion of the fluids in the presence of metals and ent study, a series of tests were run effectiveness at $316^{\circ} \mathrm{C}$. In the presin oxygen usiny a 1 percent (wt) inhibitor a different time duration at $288 \mathrm{C}$ $C_{2} \mathrm{PN}_{3}$ appear in fiyures 6 and 7 , respective concentration. Data for $P-3$ and afforded similar results showing the additive. Both series of tests same conditions except that of tests with $\mathrm{C}_{2} \mathrm{PN}_{3}$ were performed under the These data appear in figure 8. Here degradation ( 0.2 percent wt) was used. duration time, but surprisingiy, the loss of effectiveness gradualiy with test same exposure range as that observed for the 1 percent concentration tests
$(\sim 100 \mathrm{hr})$. A summary of these three sets of data more cleariy illustrates the similar behavior.

\section{Metal Corrosion}

In the absence of inhibition, extensive corrosion of the surface occurred. This is illustrated in the scanning electron microyraph of an $M-50$ occurred in the presence of inhibitor In contrast, little surface corrosion maynification).

Comparison of the as received M-50 coupon and the M-50 coupons from the two different inhibitor tests appears in figure 12. It appears that the phos ing the M-50 surface, even though the perfluorophenyl phosphine in protect- 
A scanning electron micrograph of the M-50 coupon from test. $37(P-3$ inhibitor) is shown in figure 1,3. The surface has a pocked appearance con. sisting of small dark spots and larger light areas. Results of local enorgy Atomic ratios for chromfum and vanadium areas also appear on figure 13. areas. Also included are the cruv ratios tor an $M$. iron) appear for both

the liynt areas whilocal depletion of chromium and vanadium has occurred in resultis for large area bidx analyses for occurred in the dark areas. The 37 and 38 as woll as an uinused specimen appear in table surface for tests 36 , dium surface composition. causes or allows some surface etching, the perfiluorophenyl phosphine additive exposes local concentrations of chromium and vanadium.

\section{Degradation Mechanism}

Results reported earlier (ref. 13) indicated that, in the presence of metals and oxyyen, the unbranched perfluoroalkylethers are degraded via chain of branched perfluoroalkylethers findings of Gumprecht (ret. 10) in his studies the formation of $\mathrm{COF}$ and $\mathrm{C}_{2} F_{5}$ terminated mechanisin postulated (ref. 10) leads to ure 14. Analysis of the products obtained from and is illustrated in figethers, by combined gas chromotography and from the unbranched perfluoroalkylmechanism also applies. To tacilitate and mass spectrometry, showed that this were transformed into methyl ester species. materials undergo extensive fraymentation. Unfortunately, the unbranched This associated with the absence of molecular ions prevented the tron impact. tion of compounds other than those presented in figure 14 .

\section{SUMMARY OF RESULTS}

Thermal oxidative degradation of unbranched (Fomblin 2) perfluoroalkylether's was investiyated in the presence of selected metals and alloys.

1. Chain scission was the mechanism of degradation by metals and alloys

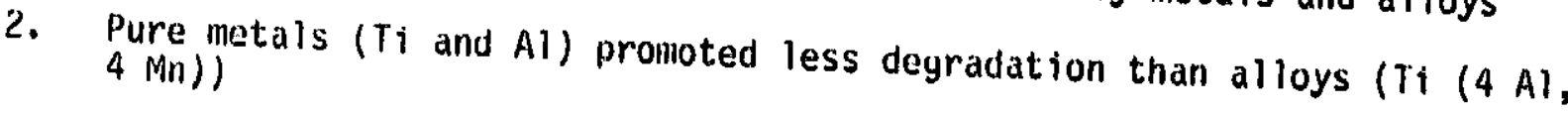

3. Inhibiturs (perfluorophenyl phosphine and phosphatriazine) retarded deg-
radation by several orders of magnitude

4. Both inhibitors were effective in the unbranched fluids for about the same time period ( 75 to $100 \mathrm{hr})$, but the phosphatriazine yielded better
protection of the metal surfaces. 


\section{REFERENCES}

1. Gumprecht. W. H. ASLE Trans., 9, 24 (1966).

2. Stanest, D., Zambonl, V., Fontanelli, R. and Btnaght, M. Wear. 10, 85 (1971).

3. Snyder, C. E., Jr., and Dolle, R. L., Jr. ASLE. Trans., 19, 171 (1976).

4. Jones, W. R., Jr. Johnson, R. L., Winer, W. 0. and Sanborn, D. M. ASL.E Trans., 18, 249 (1975).

5. Jones, W. R., Jr., and Snyder, C. L., Jr. ASLE Trans., 23, 253 (1980).

6. Snyder, C. E., Jr., Gschwender, L. J. and Campbe11, W. B. Lubr. Eng..

7. Sianesi, D. Chim. Ind. (Milan), 55, 208 (1973).

8. Snyder, C. E., Jr., Gschwender, L. J. and Tamborski, C. Lubr. Eng., 37,
$344(1981)$.

9. Paciorek, K. J. L., Kratzer, R. H., Kaufman, J. and Nakahara, J. H. J. Appl. Polym. Sci., 24, 1397 (1979).

10. Gumprecht, W. H., "The Preparation and Thermal Behavior of Hexafluoropropylene Epoxide Polymers, "Fourth International Symposium on Fluorine Chemistry, Estes Park, Colorado, July 1967.

11. Jones, W. R., Jr., Paciorek, K. J. L., Ito, T. I. and Kratzer, R. H. "Thermal Oxidative Degradation Reactions of Linear Perfluoroalkylethers", National Aeronautics and Space Administration, NASA TM-82834, 1982. 12. Snyder, C. E. Jr., Tamborski, C., Gopal, H. and Svisco, C. A. Lubr. Eng.,

13. Kratzer, R. H., Paciorek, K. J. L., Kaufman, J., and Ito, T. I. J. Fluorine Chem., 10, "“" (1977).

14. Paciorek, K. I.., Kratzer, R. H., Kaufman, J., and Nakahara, J. H., "Determination of Fluorocarbon Ether Autoxidative Degradation Mechanism," Wright-Patterson Air Force Base, AFML-TR-77-150, 1977.

15. Paciorek, K. L., Ito, T. I., and Kratzer, R. H., "Thermal Oxidative Degradation Reactions of Perfluoroalkylethers," Uitrasystems, Inc., SN-1020-
A1-F, NASA CR-165516, 1981. 
TABIE I. - FFFECT OF METALS AND INHIBITORS ON THE THERMAL OXIOATIVE BEHAVIOR OF UNBRANCHED PERFLUOROALKYIETHER IN OXYGEN

\begin{tabular}{|c|c|c|c|c|c|}
\hline Tosta & $\begin{array}{l}\text { Sampla } \\
\text { size, } 9\end{array}$ & Temporature, & Matal & Inhtbitor & $\begin{array}{c}\text { Degradation } \\
\text { rate, } \\
\text { mg/lg.hr }\end{array}$ \\
\hline 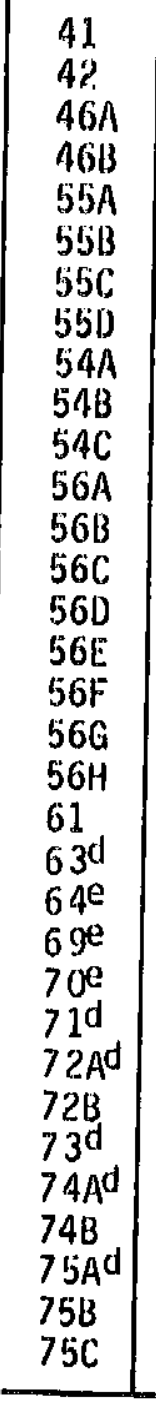 & $\begin{array}{r}3.84 \\
3.67 \\
3.60 \\
3.58 \\
4.94 \\
4.92 \\
4.91 \\
4.90 \\
3.81 \\
3.81 \\
3.80 \\
4.03 \\
4.02 \\
4.02 \\
4.01 \\
4.01 \\
4.01 \\
4.00 \\
4.00 \\
2.82 \\
30.17 \\
3.20 \\
3.54 \\
3.64 \\
30.00 \\
3.15 \\
3.10 \\
3.67 \\
3.56 \\
3.42 \\
3.50 \\
3.16 \\
2.93\end{array}$ & $\begin{array}{l}288 \\
288 \\
280 \\
288 \\
288 \\
288 \\
288 \\
288 \\
288 \\
288 \\
288 \\
288 \\
288 \\
288 \\
288 \\
288 \\
288 \\
288 \\
288 \\
292 \\
343 \\
288 \\
\dot{1} \mathrm{u} 8 \\
288 \\
343 \\
288 \\
288 \\
288 \\
288 \\
288 \\
288 \\
288 \\
288\end{array}$ & 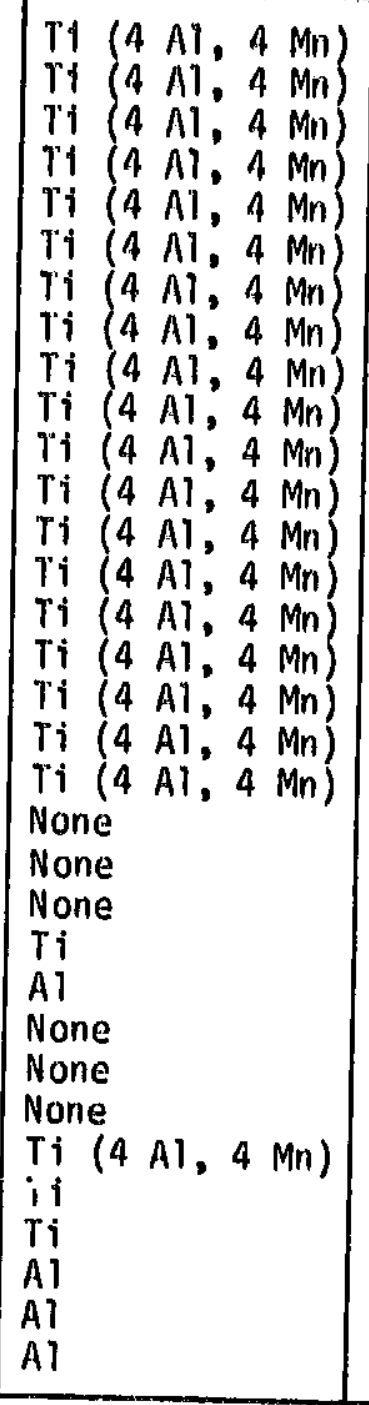 & 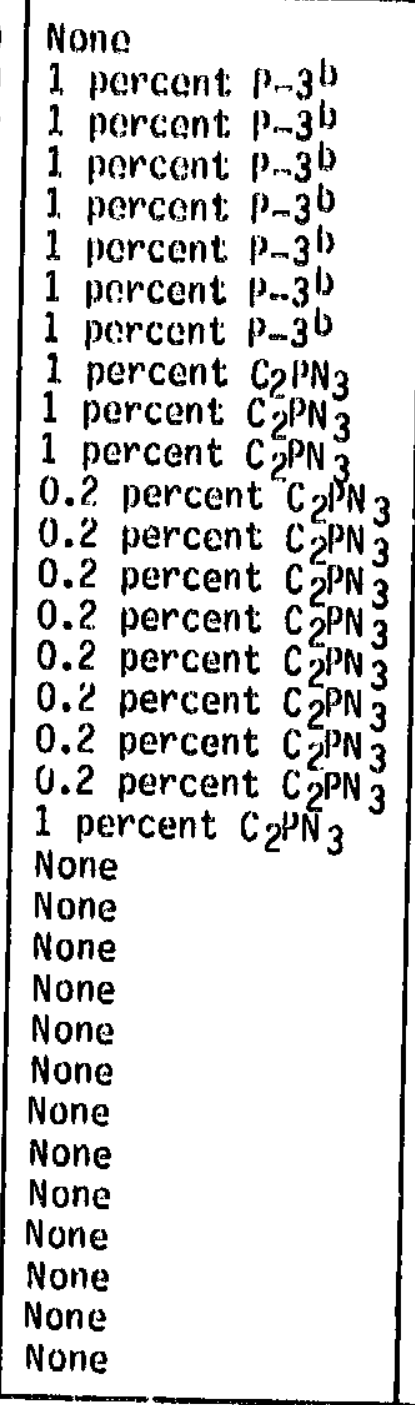 & \begin{tabular}{|cc}
72.8 & $(8)^{f}$ \\
0.047 & $(24)$ \\
0.032 & $(72)$ \\
5.0 & $(48)$ \\
0.026 & $(86)$ \\
0.11 & $(16)$ \\
0.19 & $(8)$ \\
1.72 & $(16)$ \\
0.028 & $(24)$ \\
0.014 & $(48)$ \\
3.37 & $(28)$ \\
0.040 & $(24)$ \\
0.043 & $(24)$ \\
0.066 & $(24)$ \\
0.13 & $(8)$ \\
0.10 & $(8)$ \\
0.13 & $(8)$ \\
0.24 & $(8)$ \\
27.2 & $(24)$ \\
0.035 & $(24)$ \\
0.39 & $(24)$ \\
3.45 & $(24)$ \\
48.2 & $(8)$ \\
30.2 & $(8)$ \\
0.42 & $(24)$ \\
0.51 & $(24)$ \\
0.45 & $(24)$ \\
75.9 & $(8)$ \\
5.6 & $(8)$ \\
29.6 & $(16)$ \\
12.3 & $(8)$ \\
7.9 & $(8)$ \\
4.13 & $(16)$ \\
\end{tabular} \\
\hline \multicolumn{6}{|c|}{ 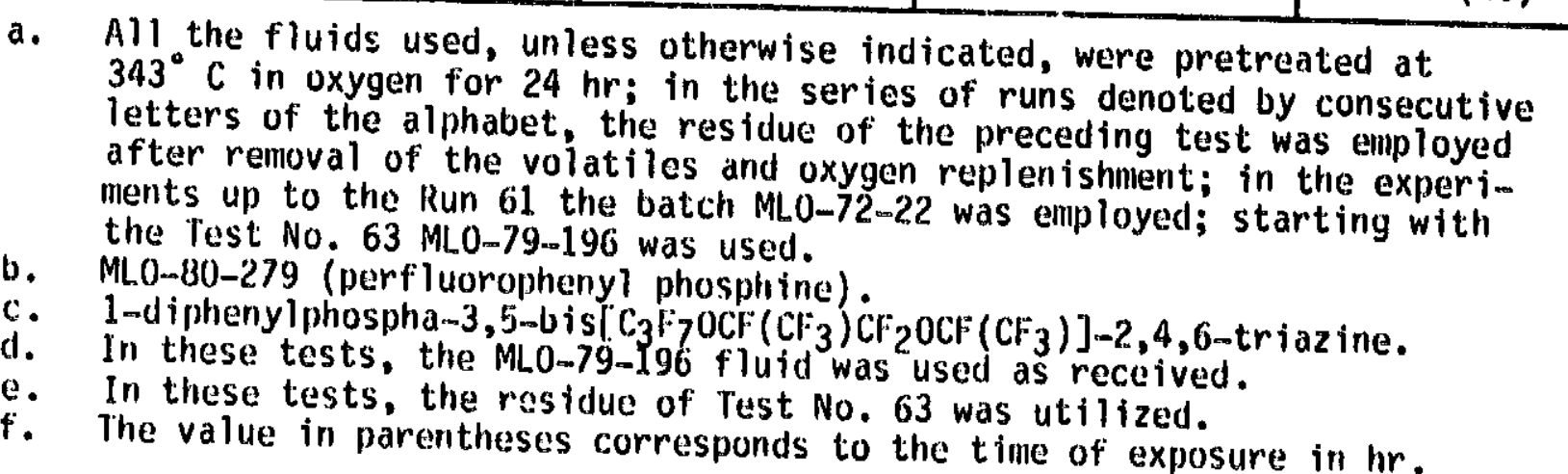 } \\
\hline
\end{tabular}


TABI.F: II. - CIIROMIUM ANI) VANADIUN, CONCFNTRATION (RAIIOFO TO FO) FOR M-G0 METAL DE:TERMINE:O

BY LNERGY DISPERSIVI: X-RAY ANALYYSIS

\begin{tabular}{|c|c|c|c|}
\hline Test: & Inhibitor & $\mathrm{Cr}$ & v \\
\hline $\begin{array}{l}\text { Unused M-50 } \\
36 \\
3 \% \\
38\end{array}$ & $\begin{array}{l}\text { Monophosphars-iriazine } \\
\text { Perfluorophenyi phosphine } \\
\text { None }\end{array}$ & $\begin{array}{r}0.105 \\
.103 \\
.104 \\
.102\end{array}$ & $\begin{array}{r}0.043 \\
.045 \\
.044 \\
.045\end{array}$ \\
\hline
\end{tabular}


$\mathrm{C}_{3} \mathrm{~F}_{7} \mathrm{O}\left[\mathrm{CF}(\mathrm{Cr})_{3} \mathrm{CF}_{2} \mathrm{O}\right]_{\mathrm{n}} \mathrm{C}_{2} \mathrm{~F}_{5}$

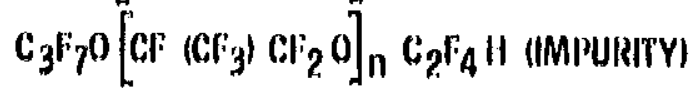

(a) Branchod flulds (krytox).

$\mathrm{CF}_{3} \circ\left[\left(\mathrm{CF}_{2}\right) \times 0\right]_{\mathrm{n}} \mathrm{CF}_{3}$

WHERE $X n 1,2, \ldots . m$

$$
x \cdot 1>x-2>>x \cdot 3
$$

(b) Unbranched fluids (fombilin Z).

Figure 1. - Chemical structuros of perfluoroalkylether fluids.

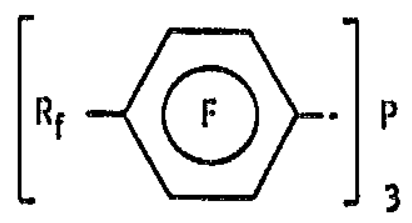

(a) Perfluorophenyl phosphine (P - 3).<smiles></smiles>

(b) Monophospha-s-tria. zine (C $\left.{ }_{2} \mathrm{PN}_{3}\right)$.

Higure 2, - chemical structures of degradation inhibitors. 

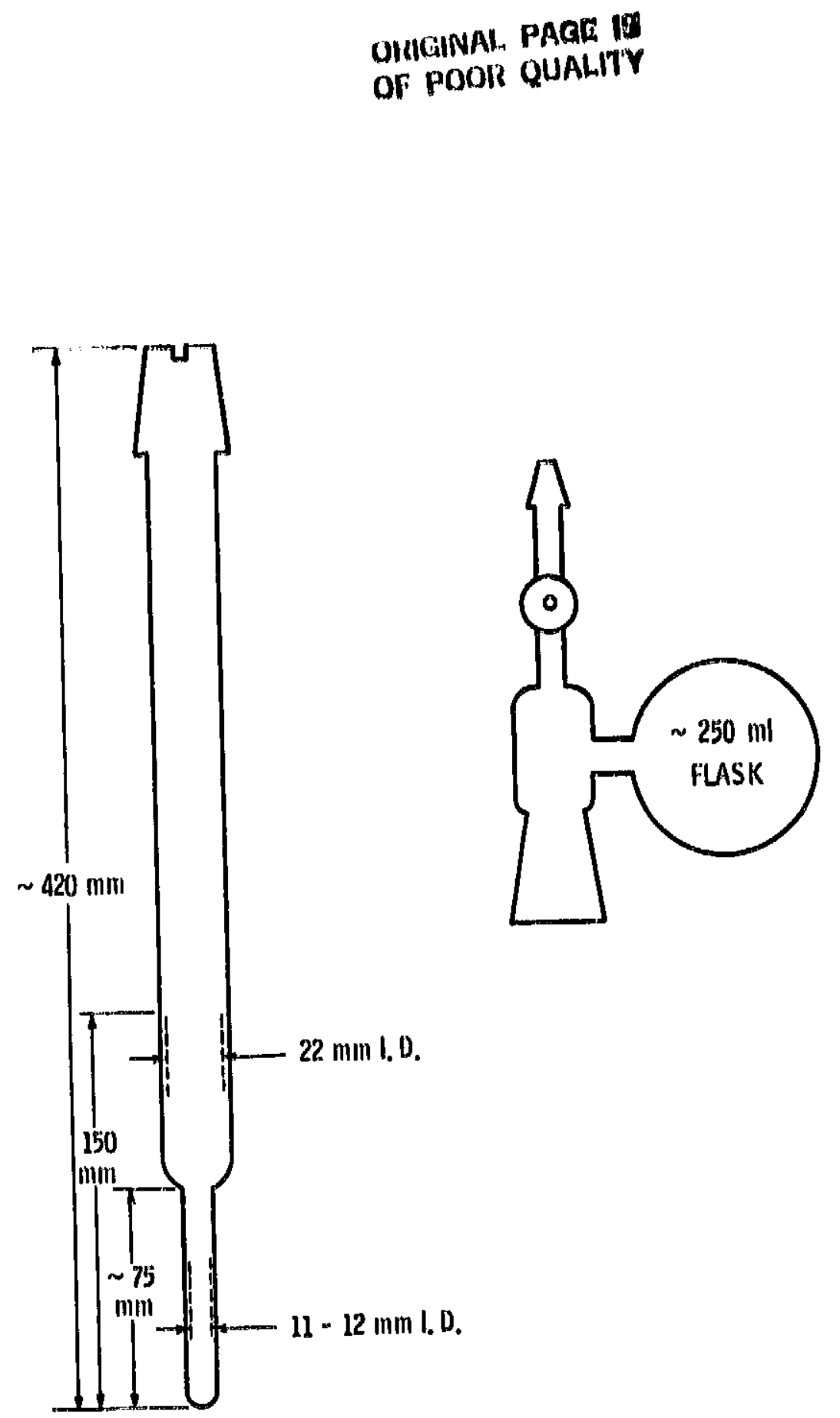

Flgure 3. - Decomposition tube and adapter. 
ORIGINAL. IOALI: Ha

OF lOOOHO QUALIITY

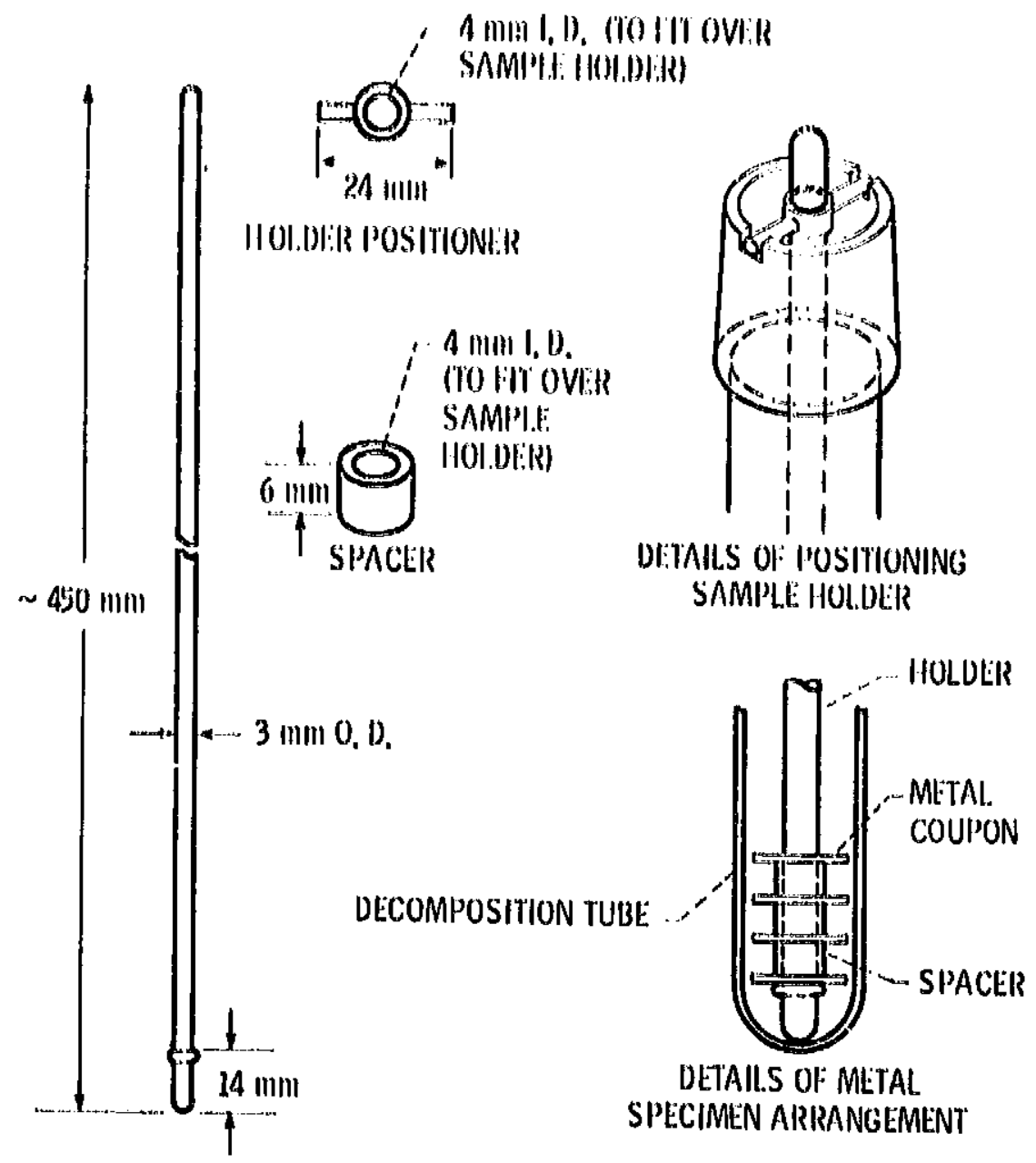

Figuro 4. - Metal specimen holder arrangement. 


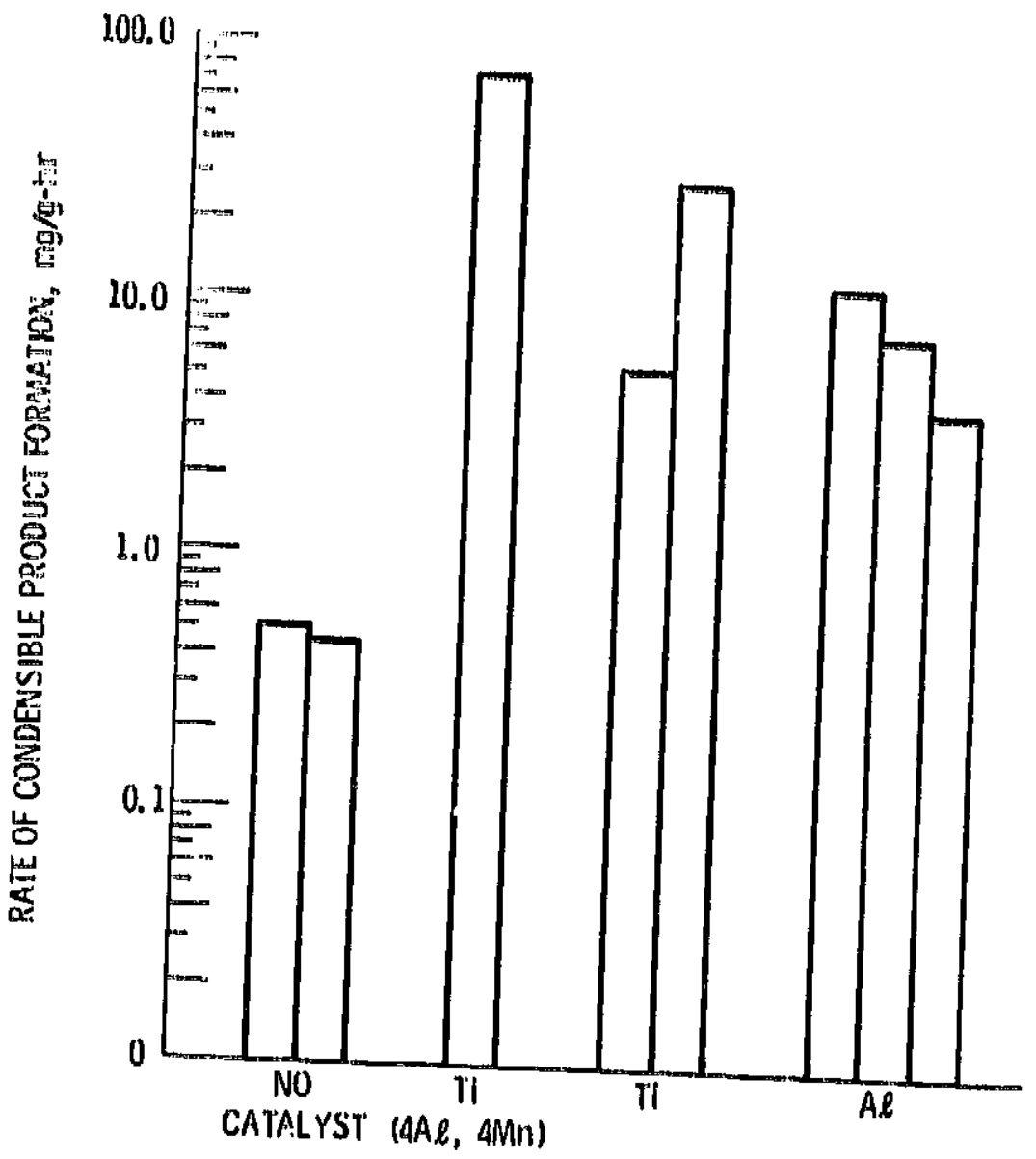

Figure 5. - Eiffect of metals or the degradation of unbranched perfluoroalkylether (MLO 79-196) (288 $\left.\mathrm{C}, \mathrm{O}_{2}\right)$. 


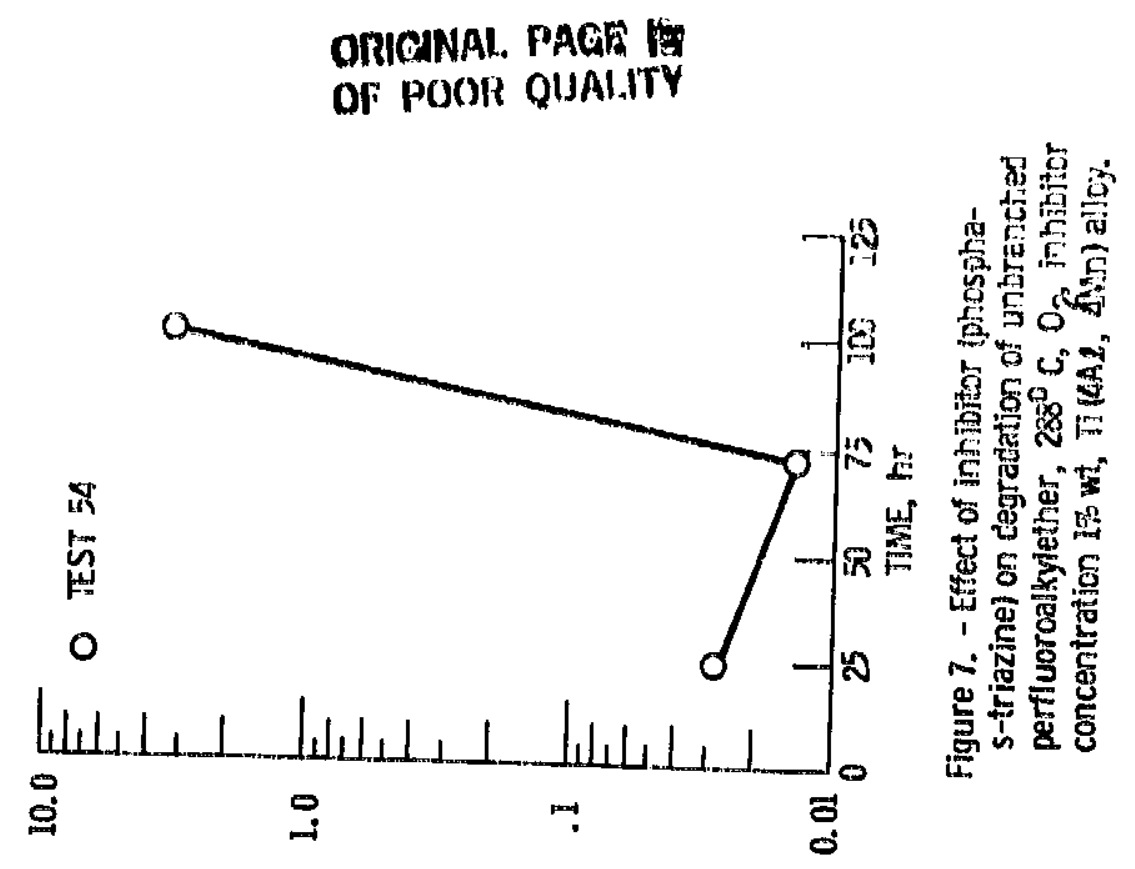

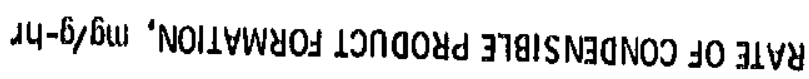

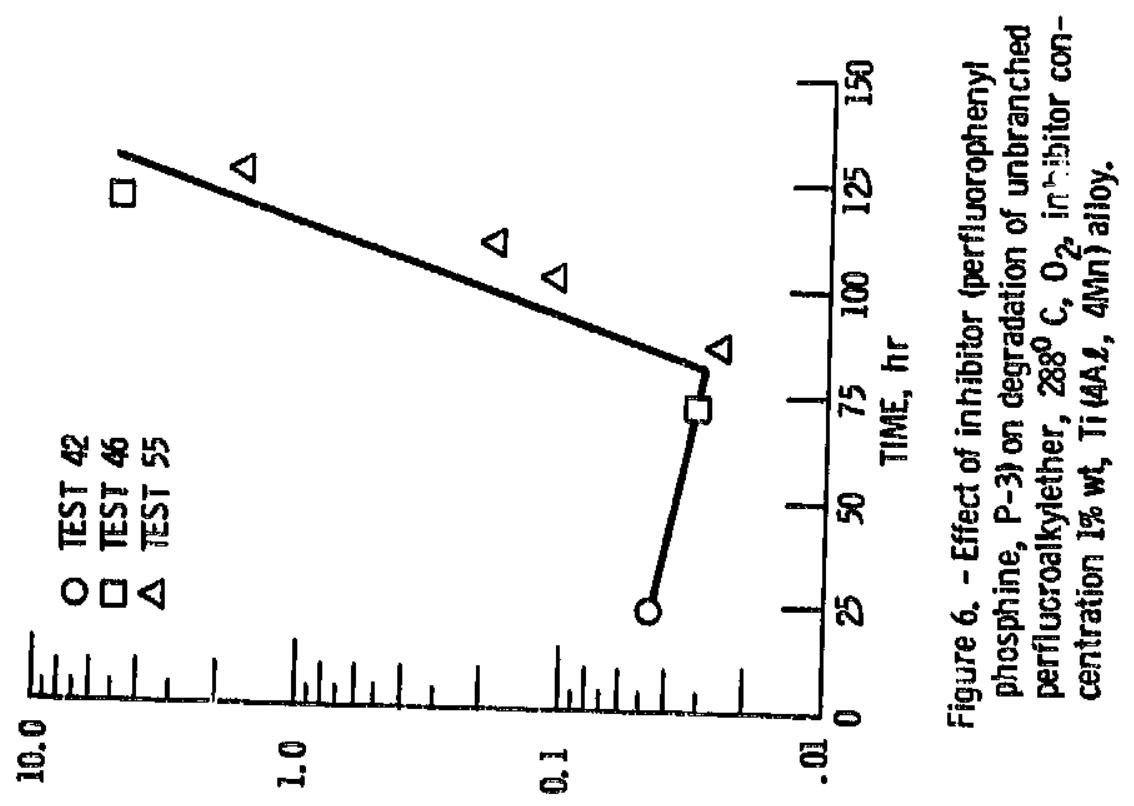

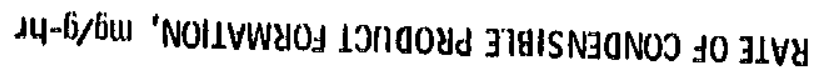




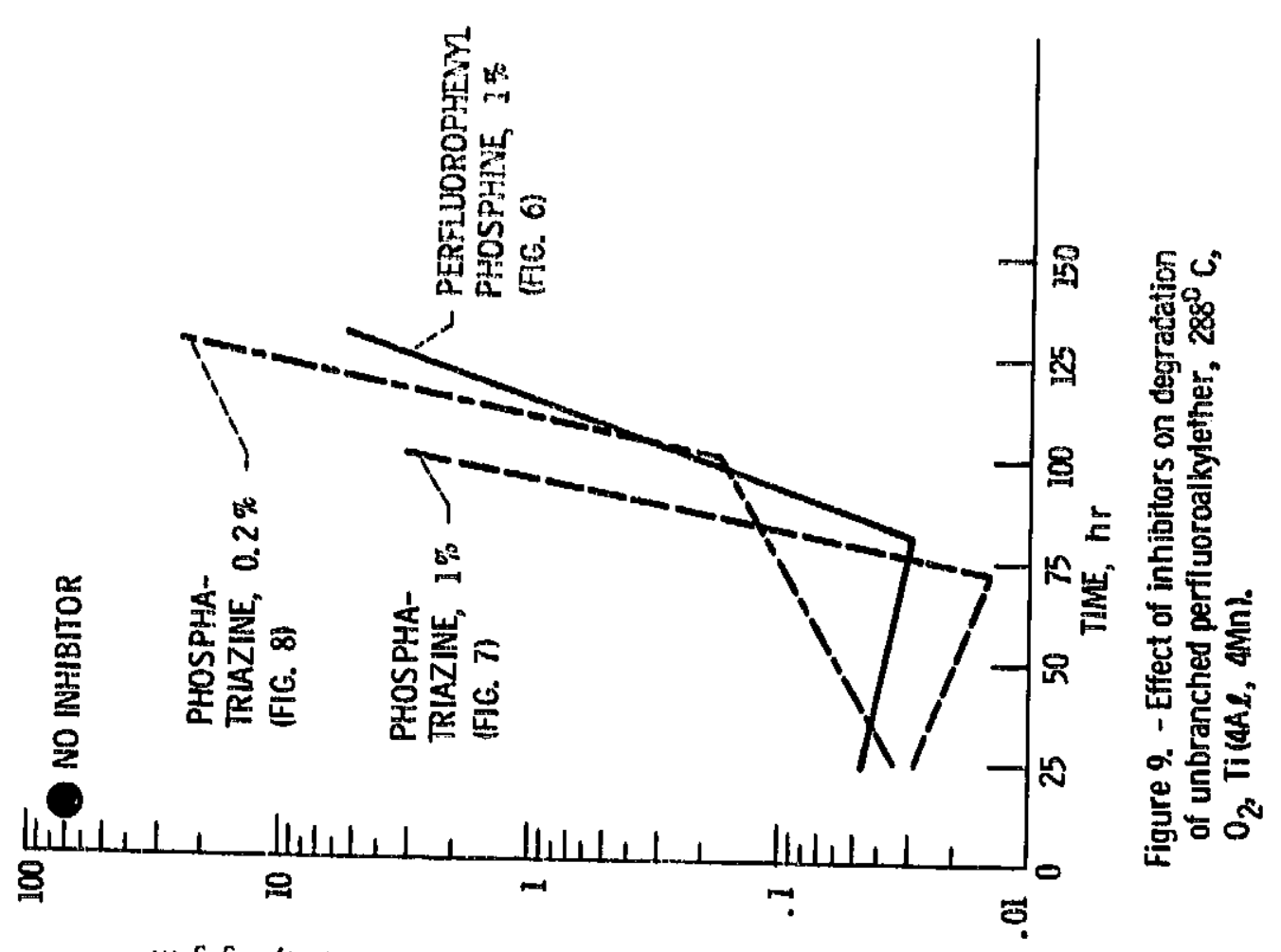

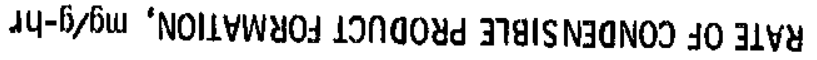

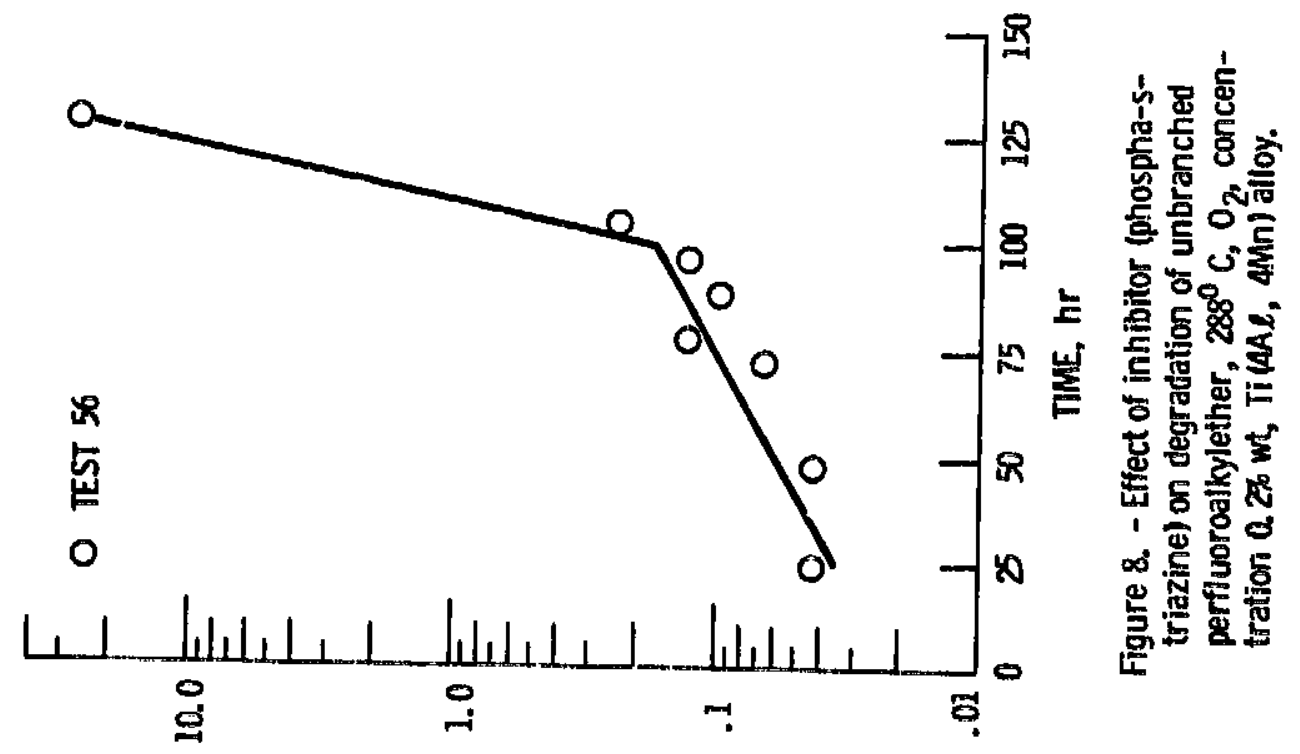

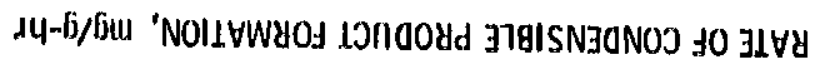




\section{ORIGINAL PACF VE \\ OF POOR QUALITY}

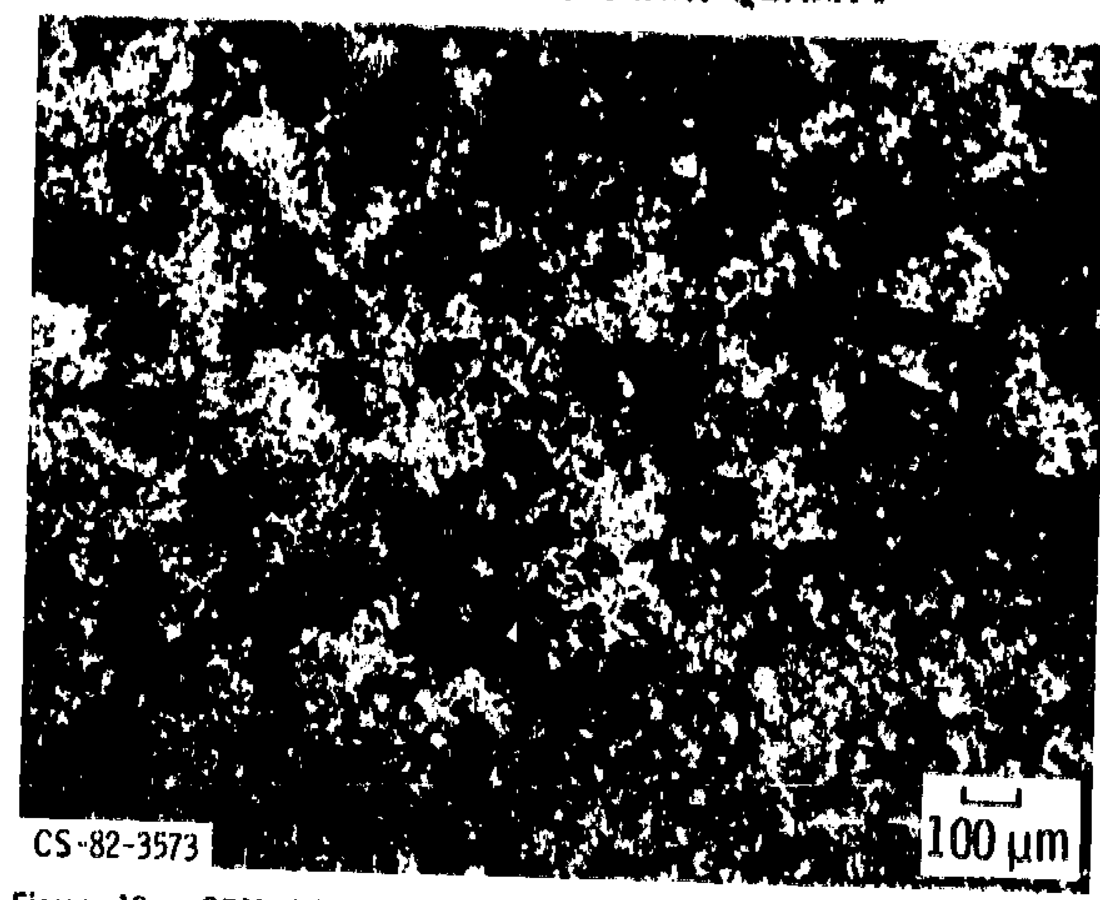

Figure 10. - SEM of $\mathrm{M}$-50 metal from test 38 (unbranched perfluoroalkylether, $288^{\circ} \mathrm{C}, \mathrm{O}_{2}$, no inhibitor), (ref. 11).

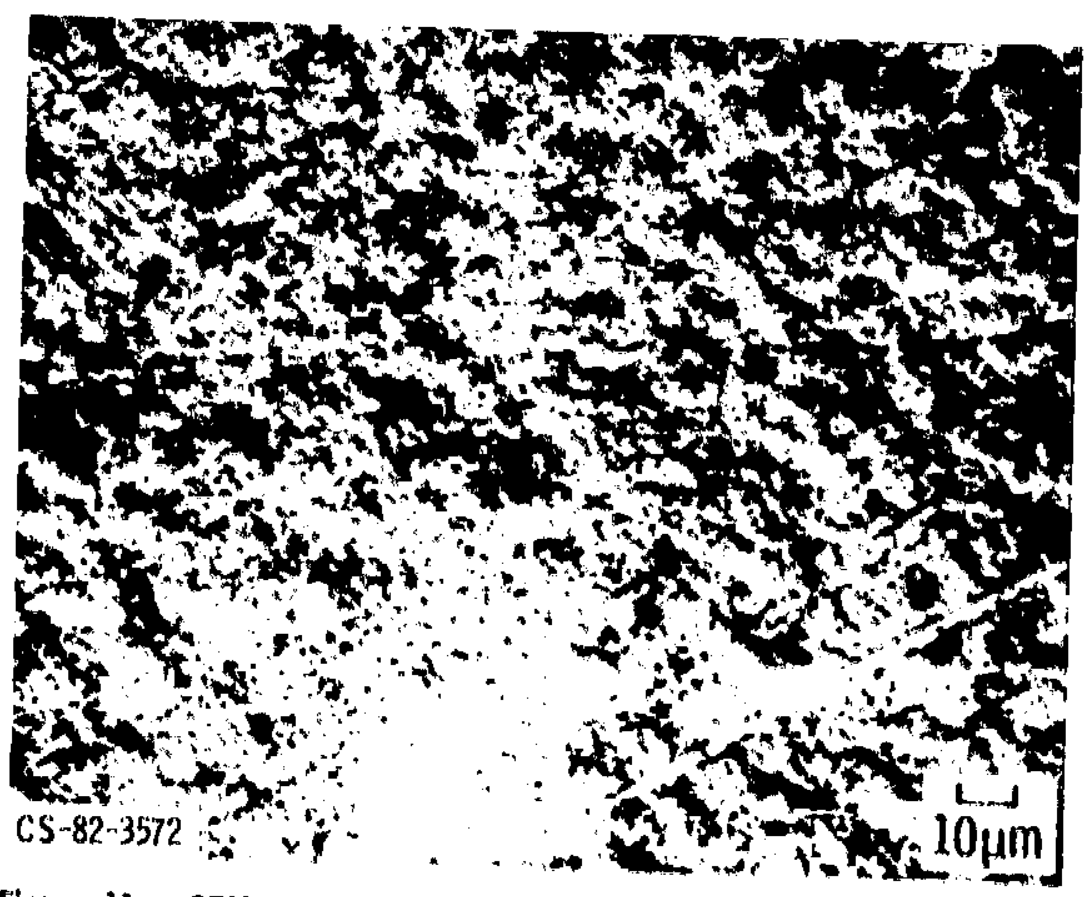

Figure 11. - SEM of M-50 metal from test 37 (unbranched perfluroalkylether, $288^{\circ} \mathrm{C}, \mathrm{O}_{2}$. perfluorophenyl phosphine inhibltor), (ref. 11). 

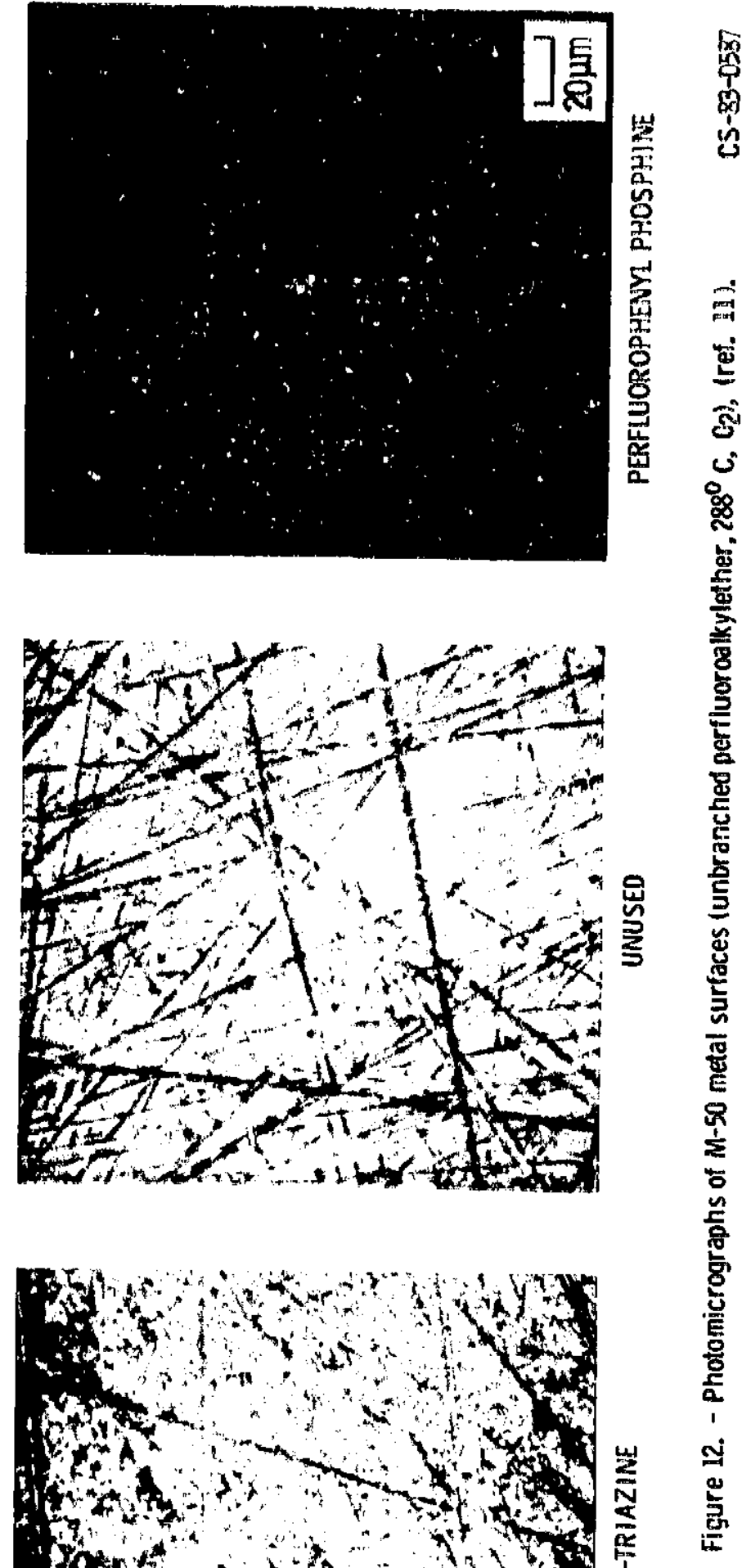
ORIGIAL PAGEF GQ

OF POOR QUALITY

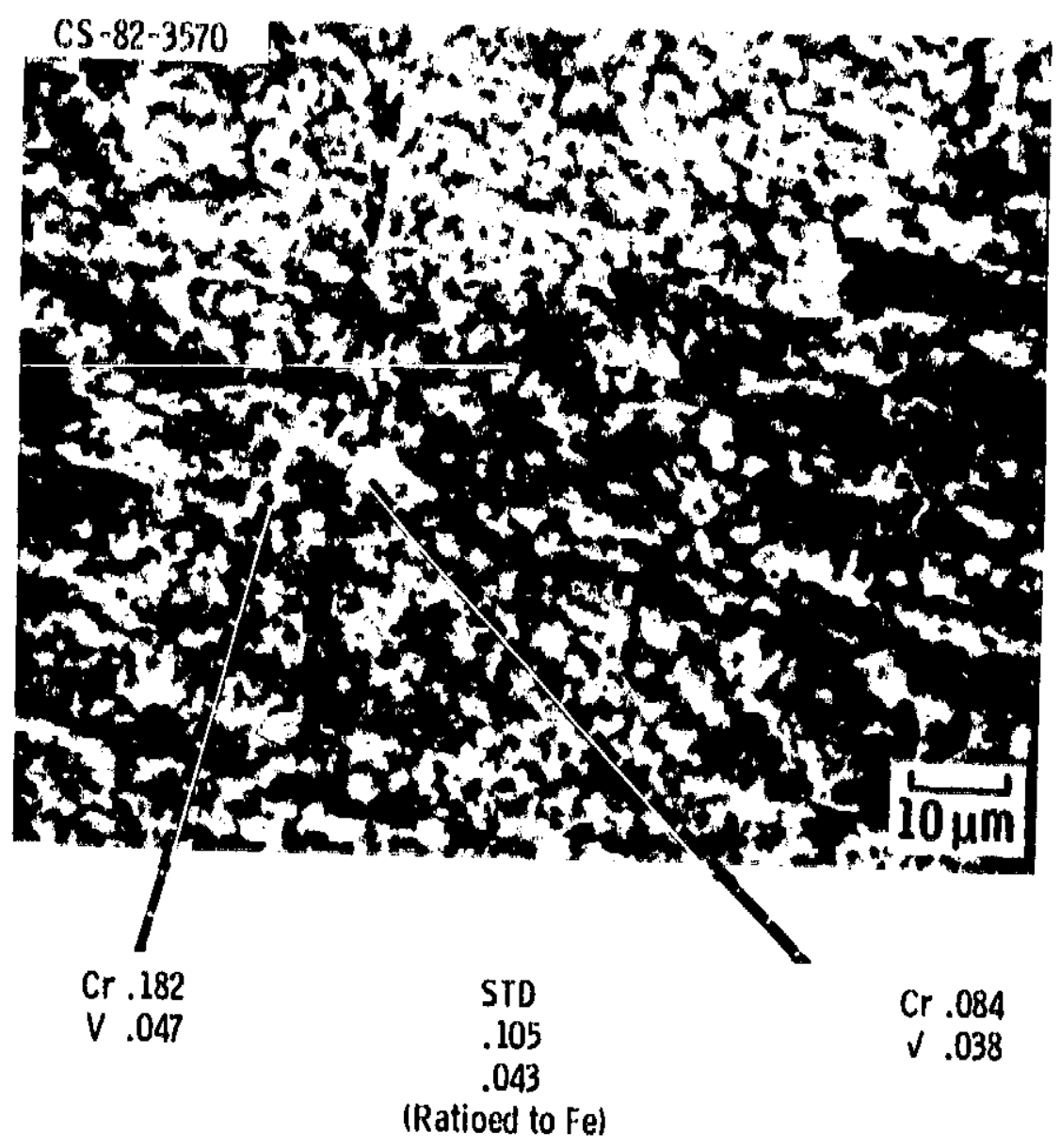

Figure 13. - SEM of M-50 metal from test 37 (unbranched perfluoroalkylether, $288^{\circ} \mathrm{C}, 0_{2}, \mathrm{P}-3$ inhibitor), (rei. 11). 
ORIGINAL PACE II

OF POOR QUALITY

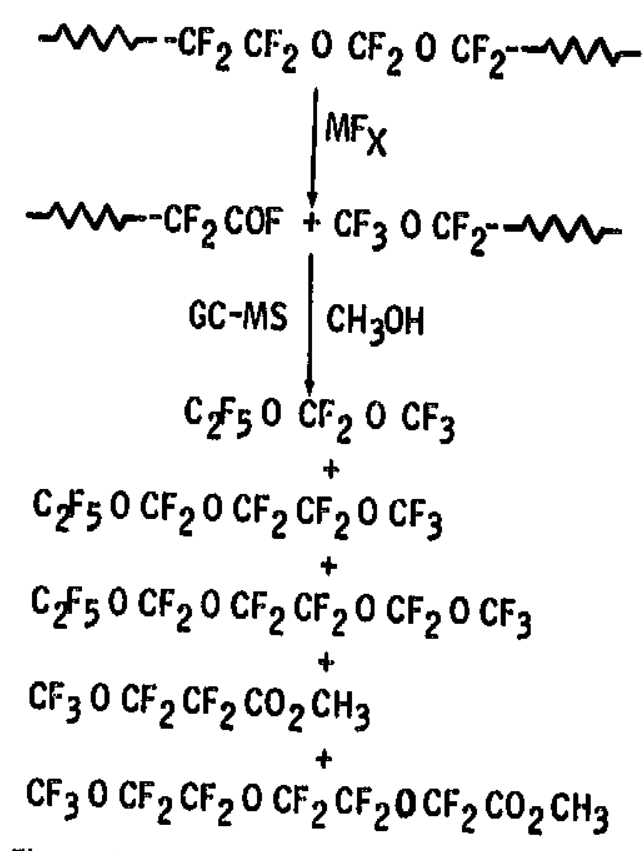

Figure 14. - Degradation of an unbranched perfluoroalkylether in the presence of Tl $(4 A \ell, 4 M n)$ at $288^{\circ} \mathrm{C}$ in $\mathrm{O}_{2}$. 